\title{
Dairy Producers' Market Participation Decision and Volume of Milk Supply in Mekelle City, Ethiopia
}

\author{
Hailay Girmay ${ }^{1}$, Belaineh Legesse ${ }^{2}$, Abebe Ejigu ${ }^{3} \&$ Seare Tajebe $^{4}$ \\ ${ }^{1}$ Haramay University, Ethiopia \\ ${ }^{2}$ Haramay University, College of Agriculture and Environmental Sciences, Ethiopia and Frontier Consulting PLC, \\ Addis Ababa, Ethiopia \\ ${ }^{3}$ Mekelle University, College of Business and Economics, Ethiopia \\ ${ }^{4}$ Aksum University, College of Agriculture, Ethiopia \\ Correspondence: Hailay Girmay, Haramay University, Ethiopia. E-mail: hailay1girmay1 @ gmail.com
}

Received: February27, 2020 Accepted: April15, 2020 Online Published: May10, 2020

doi:10.5539/sar.v9n3p21 URL: https://doi.org/10.5539/sar.v9n3p21

\begin{abstract}
This study was intended to examine dairy producers' market participation decision and volume of milk supply. Cross-sectional data was obtained from 220 sample households and analyzed using Heckman selection model. Heckman first-stage model result shows that age of household head, access to market information, access to extension service, contract agreement and accessibility of animal feed was positively determined dairy producers' milk sale decision. Heckman second-stage model result shows that access to market information, market price, accessibility of animal feed and family size was positively determined volume of milk supply, whereas religion determined negatively. This implies that dairy producers capacity building, improving information delivery system and strengthen extension service are an optional solution to improve milk production and market supply decision.
\end{abstract}

Keywords: milk sale decision, Heckman selection model and volume of milk supply

\section{Introduction}

Considerable potential for smallholder income and employment opportunity from dairy sector in Ethiopia was expected to contribute poverty alleviation and nutrition. Ethiopia is the top ranked country from livestock population in Africa, but the potential is not fully exploited. In the country, absence of sustainable dairy development causes shortage of milk supply (FAO, 2011). Effective vertical coordination among dairy value chain actors can lead higher business productivity and reduce food safety uncertainty. The mechanisms and key driving forces of the relationships is critically important (Fischer, 2001). Market participation is an essential strategy for poverty reduction and ensuring food security of peoples living in developing countries (Berhanuet al., 2007). Ample amount of milk was produced in Ethiopia, although milk demand was very high, especially in the town centers (Zelalemet al., 2011). Lack of many households market participation is the major constraint to combating poverty (Best et al., 2005). The efficient integrated and responsive dynamism in marketing system is very important for effective resources utilization, which in turn households improve production and market participation (FAO, 2003). Although, no research has been done concerning dairy producers market participation decision and volume of milk supply in Mekelle city. This study attempts to fill the research gap and add knowledge to dairy producers and related stockholders.

\section{Methodology}

\subsection{Description of the Study Area}

The study was conducted in Mekelle city, which is located in northern part of Ethiopian high lands at $777 \mathrm{~km}$ to northern part of Addis Ababa. Geographically, it is located between $13^{0} 24^{\prime} 30^{\prime \prime}$ to $13^{\circ} 36^{\prime} 5^{\prime \prime}$ latitude and $39^{\circ}$ $25^{\prime} 30^{\prime \prime}$ to $39^{\circ} 38^{\prime} 33^{\prime \prime}$ longitude. It has an average altitude of 2200 meters above sea level with minimum, maximum and average monthly temperatures of $8.7,26.8$ and $17.6{ }^{\circ} \mathrm{C}$ respectively. The amount of rainfall is variable on average about $600 \mathrm{~mm}$ and more than $70 \%$ falls between July and August and followed by long dry season (Kibrom, 2005). Mekelle city has an estimated human population of 215,546; from which $48.6 \%$ and $51.4 \%$ 
was males and females respectively. The total population $60 \%, 37 \%$ and $4 \%$ was active labor force, children below 15 years and old age more than 65 years old respectively (CSA, 2009). Dairy industry is one of the sector that are currently expanding in the town and it is supporting by the government through recruiting extension agents and veterinary technicians target to youth job opportunity, food security and improve nutrition. Currently, around 12,000 dairy enterprises are available and considered as basic business resource in the town.

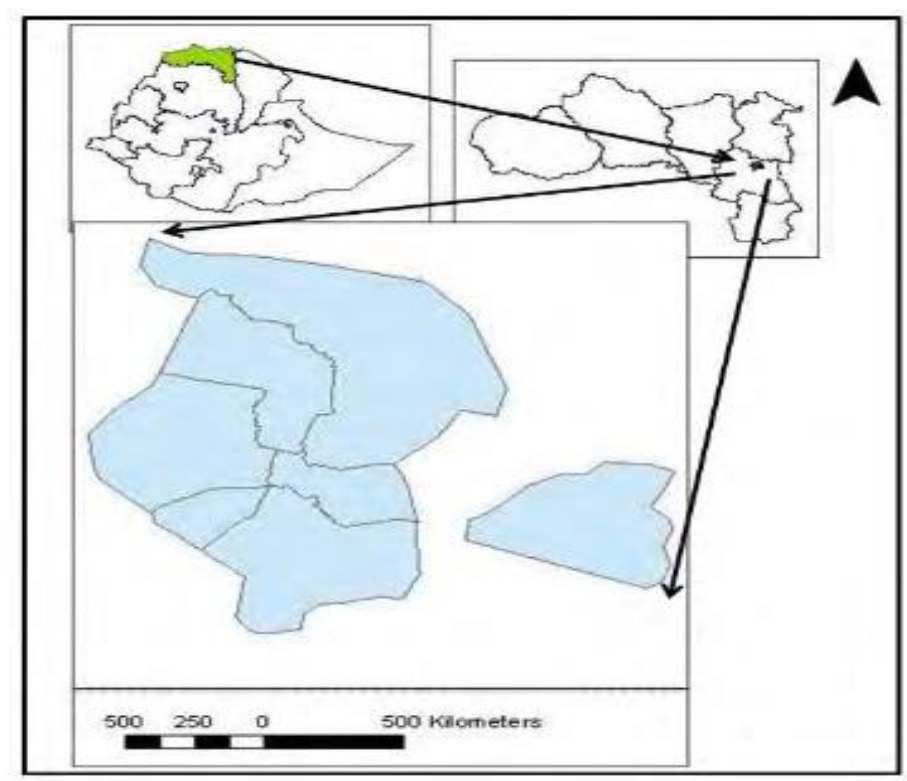

Figure 1. Geographical location of the study area

Source: Tahir et al., (2012)

\subsection{Data Type, Source and Methods of Data Collection}

This study was conducted based on primary data gathered through cross-sectional survey data collection method, which is time saving and cost effective to implement the study (Kothari, 2004). Therefore, this study was designed to undertake cross-sectional survey through semi-structured questionnaire and key informant interview.

i) Semi-structured questionnaire: It is used to collect primary data from sample households about milk sale decision and its volume. Both closed and open-ended questions were used to collect the required information. The semi-structured questionnaire that had been prepared in English was translated into Tigrigna, which is official and widely spoken language in the study area. Before actual data collection, the questionnaire was pre-tested to ensure clarity, validity and reliability of the questions. The questionnaire was pre-tested in each selected sub-cities and revised according to feedback obtained. Then, the final version of the questionnaire was employed to collect the relevant data from the sample households. The enumerators were recruited in each sub-cityto ensure that they are knowledgeable about the local agricultural activities. Moreover, the selected enumerators were trained by the principal researcher on the techniques of administering the questionnaire. This involves explaining in detail all the questions to the enumerators. This was done to ensure that the enumerators understood the questions and minimizing enumerator bias and related errors.

ii) Key informant interview: This was used to generate in-depth information from the key informants concerning dairy producers' market participation decision and its volume. This helps to understand better the issues that were raised and to triangulate the answer provided by the respondents. Checklists were prepared to collect the relevant information through non-structured interview. Key informant interview was conducted with extension agents in each sample sub-cities.

\subsection{Sample Size and Sampling Technique}

\subsubsection{Sample Size Determination}

According to Israel (1992) there are several approaches to be determining the sample size. Some of them are census study for small population, imitating sample size from similar studies, using published tables and applying formulas to calculate the sample size. Besides, one or more methods were used to guide the sample size 
determination for different combination level of precision, confidence and variability. Bartlett et al. (2001) organizational research determining appropriate sample size in survey research. The proportional sample size present in the table was calculated based on population size and data type oriented, which preferred sample size determination in this study. Three sub-cities such as Aider, Hawelti and Adi-Haqi were identified randomly from the seven sub-cities in the town and one kebele from each sample sub-city were randomly selected. Accordingly, 220 sample households were identified randomly from the sample kebeles proportional to population size.

\subsubsection{Sampling Techniques}

In this study three-stage sampling procedure were required to determine the appropriate sample size. The data was obtained from sample households identified randomly from the sample kebeles and sub-cities selected using sequential sampling procedures. In the first stage, three sub-cities were identified from seven sub-cities in the town. Second stage, one kebele from each sample sub-city was randomly identified. Finally, with 220 sample households were conducted the study selected randomly from the sample kebeles proportional to population size.

Table 1. Summary of households sample size determination

\begin{tabular}{llll}
\hline No & Sample districts & Sample kebeles & Population size \\
\hline 01 Aider & Marta & 150 \\
02 & Hawelti & Hayelom & 150 \\
03 Adi-Haqi & Hidase & 150 \\
Total & & 500 \\
Sample size & & 220 \\
\hline
\end{tabular}

Source: Own survey data 2019

\subsection{Methods of Data Analysis}

\subsubsection{Descriptive Analysis Method}

In this study, descriptive statistics method was used to analyze the demographic, socio-economic and institutional variables. Hence, descriptive statistics such as mean, percentage, frequency and standard deviation was used to describe the economic and physical characteristics associated with households' milk sale decision and its volume.

\subsubsection{Econometric Analysis}

The model Heckman was used to analyze the households'market participation decision and volume of milk supply. In the first-stage Heckman selection model, estimation was made using discrete choice decision to milk selling (households decide to milk selling take the value 1, otherwise 0). In the second-stage Heckman selection model, estimation was made using continues decision making process the households to volume of milk supply. In the first-stage Heckman selection model the equation was implemented using random utility model (Wooldridge, 2002).

$$
\begin{aligned}
& Y^{*}=Z^{\prime} \alpha+\varepsilon_{1} \\
& \mathrm{Y}=1 \text { if } \mathrm{Y}^{*}>0 \\
& \mathrm{Y}=0 \text { if } \mathrm{Y}^{*} \leq 0
\end{aligned}
$$

Where,

$Y^{*}=$ the latent variable represents discrete decision whether milk sale decision or not

$Z=$ vector of independent variables hypothesized that dairy producers milk sale decision

$Y=$ dependent variable (if dairy producers milk sale decision take the value 1 , otherwise 0 ).

$\alpha=$ parameters to be estimated

$\varepsilon_{1}=$ disturbance term

Conditional to continuous decision making process the dairy producers to volume of milk supply and which is analyzed using second-stage Heckman selection model (Heckman, 1979). The model is specified as:

$$
\begin{gathered}
Z_{i}^{*}=W_{i}^{\prime} \alpha+\varepsilon_{2} \\
\mathrm{Zi}=\mathrm{Zi}^{*} \text { if } \mathrm{Zi}^{*}>0 \\
\mathrm{Zi}=0 \text { if } \mathrm{Zi}^{*} \leq 0
\end{gathered}
$$

Where, 
$Z_{i}^{*}=$ latent variable required to desired volume of milk supply

$Z_{i}=$ the observed volume of milk supply

$W_{i}=$ the vector of covariates for unit $\mathrm{i}$ for selection equation

$\alpha=$ the vector of coefficients for selection equation

$\varepsilon_{2}=$ random disturbance term for the selection equation

In the two-stage decision making processes correlation between error terms was expected to consider as a problem, accordingly the parameter estimation also biased (Woodridge, 2002). In this case the model needs to correct the selectivity bias, which in turn Mills ratio was created using predicted probability value obtained from first-stage Heckman estimation result on the dairy producers' milk sale decision. Then, in the second-stage Heckman estimation the Mills ratio was included as one explanatory variable in the model and running the regression. The second-stage Heckman estimation equation with correction the selectivity bias was specified as follows:

$$
V=W_{i} \alpha+\lambda\left(\frac{\phi\left(W_{i} \alpha\right)}{\Phi\left(W_{i} \alpha\right)}\right)+\varepsilon_{3}
$$

Where,

$\emptyset=$ Standard normal probability density function

$\Phi=$ Standard cumulative distribution function

$\varepsilon_{3}=$ Disturbance term not correlated with $\varepsilon_{1}, \varepsilon_{2}$ and independent variables

$\lambda=$ Coefficient of Mills ratio

$V=$ Volume of milk supply

$\emptyset(.) / \Phi()=$. Mills ratio

\section{Result and Discussion}

This chapter presents the results of the study and discussions comparison with other similar studies. It is organized under two sections; the first section describes the dairy producers demographic, socio-economic and institutional characteristics using descriptive statistics. The second section examines the determinant factors that affect dairy producers' market participation decision and volume of milk supply using Heckman two-stage model.

\subsection{Statistical Description of Variables}

As statistical result indicated in the Table 2, average age of household head was 35 years old. The production was practiced by the all age groups and relatively elder age groups are practiced dairy farm alone than others mixed activity practiced. Average education level of household in formal schooling was 6 years. Producers education level helps to orient market related production and benefited from market participation. Average family size of the respondents was 4 in number. Increase household size helps to increase farm labor force and improve farm management system, but milk consumption per household was increased. Average $40 \%$ of the respondents was access to market information obtained from similar and other actors in the chain. Average 39\% of the respondents were access to extension service. Extension agents and dairy experts in the town were supporting the sector to enhance production and product marketing. Average price of milk per liter was 29.75 Birr, which is an incentive price to producers' milk sale decision. An average distance to nearest market center was $1.28 \mathrm{~km}$ far from the residence, which indicates long travel tackle the dairy producers' market participation decision.

As in the Table 2 indicated statistical result, average $73 \%$ of the respondents said that orthodox religion followers are doesn't consume dairy products during fasting periods, which in turn minimizing milk demand in some periods of the year. On average 39\% of the respondents said that local feed staffs and industrial by products were more accessible animal feed in the market. Average $39 \%$ of the respondents have contract agreement with buyers such as private consumers, institutions and further processing companies in the town. Average $37 \%$ of the dairy producers have milk collection center. Dairy producers that have milk collection center in their local area were suitable for transport in massive and known location to buyers. On average $78 \%$ of the respondents said that culture of the community was accepting milk marketing. Currently, dairy producers are adapted to milk marketing as one source of income generation in the town. 
Table 2. Descriptive statistics for milk marketing analysis

\begin{tabular}{lll}
\hline Definition of Variable & Symbol & Mean (Std) \\
\hline Age of household head (in years) & AGE & $35( \pm 12.85)$ \\
Education level of households (in formal schooling) & EDU & $6( \pm 5.44)$ \\
Family size (in number) & FS & $4( \pm 1.63)$ \\
Access tomarket information $(1=$ Yes, $0=\mathrm{No})$ & MAINF & $0.4( \pm 0.49)$ \\
Access to extension service $(1=$ Yes, $0=$ No) & EXS & $0.39( \pm 0.49)$ \\
Market price per liter of milk (in birr) & MAPRI & $29.75( \pm 1.42)$ \\
Distance to nearest market center $(\mathrm{Km})$ & MADIS & $1.28( \pm 0.45)$ \\
Accessibility of animal feed $(1=$ Yes, $0=\mathrm{No})$ & AFED & $0.39( \pm 0.49)$ \\
Contract agreement $(1=$ Yes, $0=\mathrm{No})$ & CTRGR & $0.39( \pm 0.49)$ \\
Religion(1=Orthodox, $0=$ Otherwise) & RLGN & $0.73( \pm 0.45)$ \\
Availability of milk collection center $(1=$ Yes, $0=\mathrm{No})$ & AMCC & $0.37( \pm 0.49)$ \\
Culture (1=Milk marketing, $0=$ Otherwise) & CULT & $0.78( \pm 0.41)$ \\
\hline
\end{tabular}

Source:Own survey data 2019

\subsection{Determinants of Market Participation Decision}

First-stage Heckman estimation result the probability of dairy producers' milk sale decision was present in the Table 3. The log likelihood ratio test applied to assess the overall joint significance of independent variables was explaining the variation the probability of dairy producers' market participation decision. The null hypotheses for log likelihood ratio test are all the coefficients are jointly zero. The model chi-square test applied to appropriate degree of freedom indicates that overall goodness of fit of the model is statistically significant at the probability of less than $1 \%$. This shows that jointly the independent variables included in the model were explained the variation in the probability of dairy producers market participation decision. Pseudo $\mathrm{R}^{2}$ result indicates that independent variables included in the model were explained the variation the probability of dairy producers' market participation decision about $99 \%$ predicted correctly.

Table 3. First-stage Heckman estimation result for market participation analysis

\begin{tabular}{llll}
\hline Variables & Coef. & Std. Err & $\mathbf{P}>|\mathbf{z}|$ \\
\hline TOPR & 0.001 & 0.001 & 0.525 \\
AGE & 0.001 & 0.001 & $0.082^{*}$ \\
EDU & -0.001 & 0.002 & 0.875 \\
FS & 0.001 & 0.009 & 0.991 \\
MAINF & 0.252 & 0.069 & $0.000^{* * *}$ \\
MAPRI & 0.007 & 0.006 & 0.248 \\
EXS & 0.217 & 0.076 & $0.004^{* * *}$ \\
MADIS & -0.011 & 0.021 & 0.604 \\
CTRGR & 0.196 & 0.069 & $0.005^{* * *}$ \\
CULT & 0.033 & 0.027 & 0.214 \\
AFED & 0.236 & 0.073 & $0.001^{* * *}$ \\
RLGN & -0.011 & 0.024 & 0.656 \\
\hline Cons. & -0.174 & 0.1971 & 0.378 \\
\hline Number of observations $=220$ \\
Wald chi2 12$)=475.67$ & \\
Prob> chi2=0.000 \\
\hline \% significance level respectively.
\end{tabular}

Note: $* * *$ and $*$ shows $1 \%$ and $10 \%$ significance level respectively.

Source: Author's computation from sample survey data (2019).

Age of household head (AGE): The regression result in the Table 3 shows that, age of household head has positively and statistically significant to dairy producers' market participation decision at $10 \%$ level. As the age of household head increases by one year, the probability of market participation decision was increased by $0.1 \%$. The older dairy producers are more adaptable to dairy production and marketing than young generation focus to other business. Similar studies, age of household head was positively determining the producers market participation decision (Ataul and Elias, 2015). 
Access to market information (MAINF): As in the first stage Hackman model result shows that, access to market information has positively and statistically significant to dairy producers milk sale decision at $1 \%$ level. As producers access to market information, the probability of market participation decision would be increased by 25\%. Dairy producers' access to market information was encouraged actors to market participation decision. Similar studies revealed that access to market information through different material was raising the chance to rice producers market participation decision (Lizzen M., 2015). Radio and other source of market information were considered to reducing the transaction costs and facilitating producers market participation decision (Azamet al., 2012).

Contract agreement (CTRGR): As indicated result in the Table 3, contract agreement has positively and statistically significant the dairy producers' market participation decision at $1 \%$ level. The result indicated that the probability of dairy producers get contractual agreement with buyers has increased the chance of market participation decision by $19.6 \%$. Actors get contract agreement with buyers has a great role to smooth flow of products and helps to producers' market participation decision.

Accessibility of animal feed (AVFED): In the first stage Heckman model result indicated that, accessibility of animal feed has positively and statistically significant the probability of dairy producers' market participation decision at $1 \%$ level. This indicates that as dairy producers access to animal feed the probability of market participation decision was increased by $23.6 \%$. Animal feed plays a key role to maintain farm production, besides help to dairy producers market participated decision. In the study area local feed staffs such as hay and straw and industrial by products such as wheat bran and residual cotton/sesame cake are common feed staffs accessible in the market, which helps to increase production and producers market participation decision. The study consistent with findings that shortage of animal feed affects milk production, which in turn decrease milk supply (Ngongoniet al., 2006).

Access to extension service (EXS): The regression result in the Table 3 indicated that, access to extension service was positively and statistically significant the likelihood to dairy producers market participation decision at $1 \%$ level. The result indicated that as dairy producers' access to extension service the likelihood to milk sale decision would be increased by $21.7 \%$. Extension service related to farm management and product marketing encourages dairy producers' milk sale decision. Similar studies in red bean indicated that extension service increased the red bean producers market participation decision (Abebe, 2016; Abebe and Adesina, 2015; Agete Jerena, 2014).

\subsection{Determinant of Volume of Milk Supply}

The second-stage Heckman estimation result to volume of milk supply was present in Table 4. The coefficient of Mills ratio (Lambda) in the Heckman two-stage estimation was significant at the probability of less than $10 \%$. This indicates that the presences of sample selection bias existence in some unobservable variables are captured and determined the likelihood to volume of milk supply. The overall joint goodness of fit of the model estimation was assessed based on the log likelihood ratio test. The null hypothesis for log likelihood ratio test was all the coefficients are jointly zero. The model chi-square test applied to appropriate degrees of freedom indicated that the overall goodness of fit of model was statistically significant at the probability of less than $1 \%$. This shows that jointly the independent variables included in the model was explained the volume of milk supply. 
Table 4. Second-stage Heckman estimation result for volume of milk supply analysis

\begin{tabular}{llll}
\hline Variables & Coef. & Std. Err & $\mathbf{P}>|\mathbf{z}|$ \\
\hline TOPR & 0.025 & 0.031 & 0.420 \\
AGE & 0.005 & 0.014 & 0.715 \\
EDU & -0.056 & 0.048 & 0.245 \\
FS & -0.566 & 0.231 & $0.014^{* *}$ \\
EXS & 0.192 & 1.166 & 0.869 \\
MAINF & 1.327 & 0.791 & $0.094^{*}$ \\
CTRGR & -0.010 & 1.082 & 0.993 \\
MAPRI & 0.251 & 0.150 & $0.095^{*}$ \\
MADIS & -0.539 & 0.505 & 0.286 \\
AFED & 2.843 & 1.241 & $0.022^{* *}$ \\
MAAC & 0.836 & 1.078 & 0.438 \\
RLGN & -1.167 & 0.673 & $0.083^{*}$ \\
CULT & -0.365 & 0.495 & 0.461 \\
\hline Cons. & -6.192 & 4.594 & 0.178 \\
\hline LAMBDA & -0.081 & 0.043 & $0.061^{*}$ \\
\hline Number of observations $=220$ \\
Wald chi2 $(12)=475.67$ \\
Prob> chi2=0.000 \\
Rho =0.9 \\
Sigma =0.08 \\
\hline
\end{tabular}

Note: **and* shows $5 \%$ and $10 \%$ significance level respectively.

Source: Author's computation from sample survey data(2019).

Family size (FS): As Heckman two stage model result shows that, family size was negatively affected the volume of milk supply and statistically significant at 5\% level. As family size of household increased by one the probability of volume of milk supply decreased by $57 \%$. As number of family size increases, milk consumption per household level increases inversely to volume of milk supply. Similar study found that family size was negatively affected to red bean producers' level of market participation decision (Agete Jerena, 2014).

Access to market information (MAINF): As in the Table 4 result indicted that, access to market information was positively and statistically significant the dairy producers volume of milk supply at $10 \%$ level. As dairy producers access to market information, the volume of milk supply was increased by 1.33 liter. Market information was very important to chain actors for market condition identification, which helps to quantity of milk sale decision. Similar studies support that availability of price information and knowledge prior to product selling was reduced transaction cost and increase quantity product sold (Randela et al., 2008; Omiti et al., 2009).

Market price (MAPRI): As second stage Heckman model result shows that, market price was positively affected the volume of milk supply and statistically significant at $10 \%$ level. The price of milk per liter was increased by one birr and the volume of milk supply was increased by 0.25 liter. As price of milk increases, the dairy producers stimulate to provide more milk supply to the market. Related studies showed that access to market information concerning price was increased the chance of rice producers market participation decision and volume of rice supply (Lizzen M., 2015).

Accessibility of animal feed (AVFED): The regression result in the Table 4 indicated that, accessibility of animal feed was positively and statistically significant the likelihood to volume of milk supply at $5 \%$ level. Accessibility of animal feed increases, the probability of volume of milk supply was increased by 2.84 liter. The local feeds such as hay and straw and industrial products such as wheat bran and residual cotton/sesame cake were common feed staffs accessible in the market, which helps to increase milk production and quantity supply to the market.

Religion (RLGN): Theregression result in the Table 4 shows that, religion was negatively and statistically significant the dairy producers' likelihood to volume of milk supply at $10 \%$ level. As peoples follow to orthodox religion the probability of volume of milk supply was decreased by 1.17 liter. The result indicates that most of the orthodox religion followers are doesn't consume dairy products during fasting periods of the year, which in turn decrease milk production and market supply according to demand in the market. 


\section{Conclusion and Policy Implications}

This study, dairy producers' market participation decision and volume of milk supply has been analyzed using Heckman two-stage model. The findings revealed that age of the household head, access to market information, access to extension service, contract agreement and accessibility of animal feed was positively determined to dairy producers' market participation decision. Besides, access to market information, market price, accessibility of animal feed and family size was positively determined to volume of milk supply, whereas religion determined negatively. Based on the findings, the intervention was providing to dairy producers capacity building, strengthen extension service and improving information delivery system are a vital area to enhance production and product marketing.

\section{Acknowledgement}

The College of Agriculture and Environmental Sciences, Haramaya University has speed up the entire search process. The authors are also grateful to Samara University for their cooperation throughout accomplishment of the study.

\section{References}

Abebe, E. A. (2016). Determinants of Smallholders' Preference to hybrids: Prospect for Upgrading to High Value Food Chains. Journal of Agribusiness and Rural Development, 3(41), 1-11.

Abebe, E., \& Jimi, A. (2015). Effects of Cooperatives and Contracts on Rural Income and Production in the Dairy Supply Chains: Evidence from Northern Ethiopia. African Journal of Agricultural and Resource Economics, 10(4), 312-327.

Agete, J. (2014). An analysis of factors influencing participation of smallholder farmers in red bean marketing in Halaba special district, Ethiopia. Faculty of agriculture University Of Nairobi.

Ataul, G., \& Elias, H. (2015). Market participation decision of smallholder farmers and its determinants in Bangladesh.

Azam, M. S., Imai, K., \& Gaiha, R. (2012). Agricultural supply response and smallholders market participation: The case of Cambodia. Economics Discussion Paper Series, No. 1208. Manchester, UK: Economics Department, School of Social Sciences, University of Manchester.

Bartlett, K. H. (2001). Organizational research: determining appropriate sample size in survey research.

Berhanu, G., Hoekstra, D., \& Samson, J. (2007). Heading towards commercialization? The case of live animal marketing in Ethiopia. Improving Productivity and Market Success (IPMS) of Ethiopian Farmers Project. ILRI, Nairobi, Kenya.

Best, R., Ferris, S., \& Schiavone, A. (2005). Building linkage and enhancing trade between small scale rural producers, buyers in growing markets and suppliers of critical inputs. Proceedings of the international seminar on beyond agricultural marketing. Markets work for the poor, Westminster, London, UK. p. 19-50

Central statistics agency. (2009). Population and Housing Census. Addis Ababa, Ethiopia.

FAO. (2003). FAO action program for the prevention of food lost. Milk and dairy product, post-harvest lost and food safety for Sab-Saharan Africa and the near east. Regional approaches to national challenges, synthesis report, ILRI, Addis Ababa, Ethiopia.

FAO. (2011). Food and Agriculture Organization Ethiopia Country Programming Framework.Office of the FAO Representative in Ethiopia to AU and ECA Addis Ababa 2011.

Fischer. (2001). Trust and communication in European agri-food chains. Supply Chain Management.

Heckman, J. (1979). Sample selection bias as a specification error, Econometrical. https://doi.org/10.2307/1912352

Israel, G. D. (1992). Sampling the Evidence of Extension Program Impact. Program Evaluation and Organizational Development, IFAS, University of Florida.

Kibrom, G. (2005). Investigation into engineering properties of Mekele soils with an emphasis on expansive soils. MSc Thesis, Addis Ababa University, Ethiopia.

Kothari, C. R. (2004). Research Methodology: Methods and Techniques, 2nd Edition. New Age International, New Delhi, India. 
Lizzen, M. (2015). Analysis of factors influencing market participation among smallholder rice farmers in western province, Zambia. University of Nairobi.

Lundy, M., Gottret, M., Cifuentes, W., Ostertag, C., Best, R., Peters, D., \& Ferris, S. (2004). Increasing the competitiveness of the market chains with small holder producers, filed manual; territorial approach to rural agro-enterprise development. Centro international de agriculture tropical, cali, Colombia. p. 1-117.

Mary, T., Ekwal, I., \& Tahir, H. (2012). Evaluation of land use/land cover changes in Mekelle City. Ethiopia using Remote Sensing and GIS.

Ngongoni, N. T., Mapiye, C., Mwale, M., \& Mupeta, B. (2006). Factors affecting milk production in the smallholder dairy sector of Zimbabwe. Plan International Harare, Zimbabwe.

Omiti, J. M., Otieno, D. J., Nyanamba, T., \& McCullough, E. (2009). Factors influencing the intensity of market participation by smallholder farmers: A case study of rural and peri-urban areas of Kenya. African Journal of Agricultural and Resource Economics.

Randela, R., Alemu, Z. G., \& Groenewald, J. A. (2008). Factors enhancing market participation by small-scale cotton farmers. Agrekon, 47(4), 451-469. https://doi.org/10.1080/03031853.2008.9523810

Woodridge, J. (2002). Econometric Analysis of Cross-section and Panel Data. MIT Press, USA.

Zelalem, Y., Emmannuelle, G., \& Ameha, S. (2011). Dairy sector development in Ethiopia. Edited by FAO Sub Regional Office for Eastern Africa.

\section{Copyrights}

Copyright for this article is retained by the author(s), with first publication rights granted to the journal.

This is an open-access article distributed under the terms and conditions of the Creative Commons Attribution license (http://creativecommons.org/licenses/by/3.0/). 